\title{
Cerebral air embolism after noninvasive ventilation postpulmonary wedge resection
}

\author{
Paritosh Sharma, MRCS, John E. Pilling, MRCS, and Wael I. Awad, FRCS(CTh), London, United Kingdom
}



ystemic air embolism (SAE) has been reported after pulmonary trauma, ${ }^{1}$ surgery, ${ }^{2}$ and interventional procedures, often in association with positive pressure ventilation. Cerebral air embolism (CAE), a subset of SAE, is a rare complication of thoracic procedures ${ }^{3,4}$ that causes cerebral ischemia and inflammation. CAE has been reported in association with noninvasive positive pressure ventilation (NIPPV), but never postoperatively. We report a case of CAE after initiation of NIPPV in an emphysematous patient postpulmonary wedge resection.

\section{Clinical Summary}

A 68-year-old man with a smoking habit and severe emphysema presented for surgical excision biopsy of a $2 \times 1.5-\mathrm{cm}$ irregular right lower lobe pulmonary nodule. On a positron emission tomographic scan, the lesion was fluorodeoxyglucose avid. Through a left thoracotomy, the lesion was excised with 4 firings of the EZ45 stapling device (Ethicon Endo Surgery, Cincinnati, Ohio). The patient was extubated at the end of the procedure.

Type 2 respiratory failure developed after 2 hours $\left(\mathrm{Po}_{2} 78 \mathrm{~mm} \mathrm{Hg}\right.$, $\mathrm{PCO}_{2} 81 \mathrm{~mm} \mathrm{Hg}, \mathrm{FIO}_{2} 0.6$ [facemask]). Chest radiography showed bibasal collapse. Biphasic positive airway pressure (BIPAP) was commenced (inspiratory positive airway pressure $16 \mathrm{~cm} / \mathrm{H}_{2} \mathrm{O}$, expiratory positive airway pressure $5 \mathrm{~cm} / \mathrm{H}_{2} \mathrm{O}$, oxygen $10 \mathrm{~L} / \mathrm{min}$; S/T 30 Ventilatory Support System, Respironics Inc, Pa) with a good response. Four hours after commencement of BIPAP the patient became unresponsive and his respiratory failure again deteriorated $\left(\mathrm{PO}_{2} 62 \mathrm{~mm} \mathrm{Hg}, \mathrm{PCO}_{2} 56 \mathrm{~mm} \mathrm{Hg}\right.$, on BIPAP, airway pressures unchanged, oxygen $2 \mathrm{~L} / \mathrm{min}$ ). His pupils were fixed and dilated, and he had a tonic-clonic seizure. The patient was sedated and reintubated, and a phenytoin infusion was commenced. A computed tomographic (CT) scan of the brain (Figure 1, A) showed air in the subarachnoid space. Transesophageal echocardiography did not reveal an atrial septal defect.

Seven days later, CT of the brain showed bilateral cerebral ischemic changes (Figure 1,B). The patient had severe spastic

\footnotetext{
From the Department of Cardiothoracic Surgery, London Chest Hospital, Bonner Road, London, United Kingdom.

Received for publication Nov 24, 2006; accepted for publication Dec 12, 2006.

Address for reprints: Mr W.I. Awad, MRCS, Department of Cardiothoracic Surgery, London Chest Hospital, Bonner Road, London, United Kingdom E29JX (E-mail: w.awad@barts or london.nhs.org).

J Thorac Cardiovasc Surg 2007;134:262-3

$0022-5223 / \$ 32.00$

Copyright @ 2007 by The American Association for Thoracic Surgery doi:10.1016/j.jtcvs.2006.12.050
}

paresis of all 4 limbs. He could comprehend questions and reply by eyelid movement. Histology of the excised nodule revealed a primary pulmonary adenocarcinoma. The patient was discharged and sent to a neurologic rehabilitation unit.
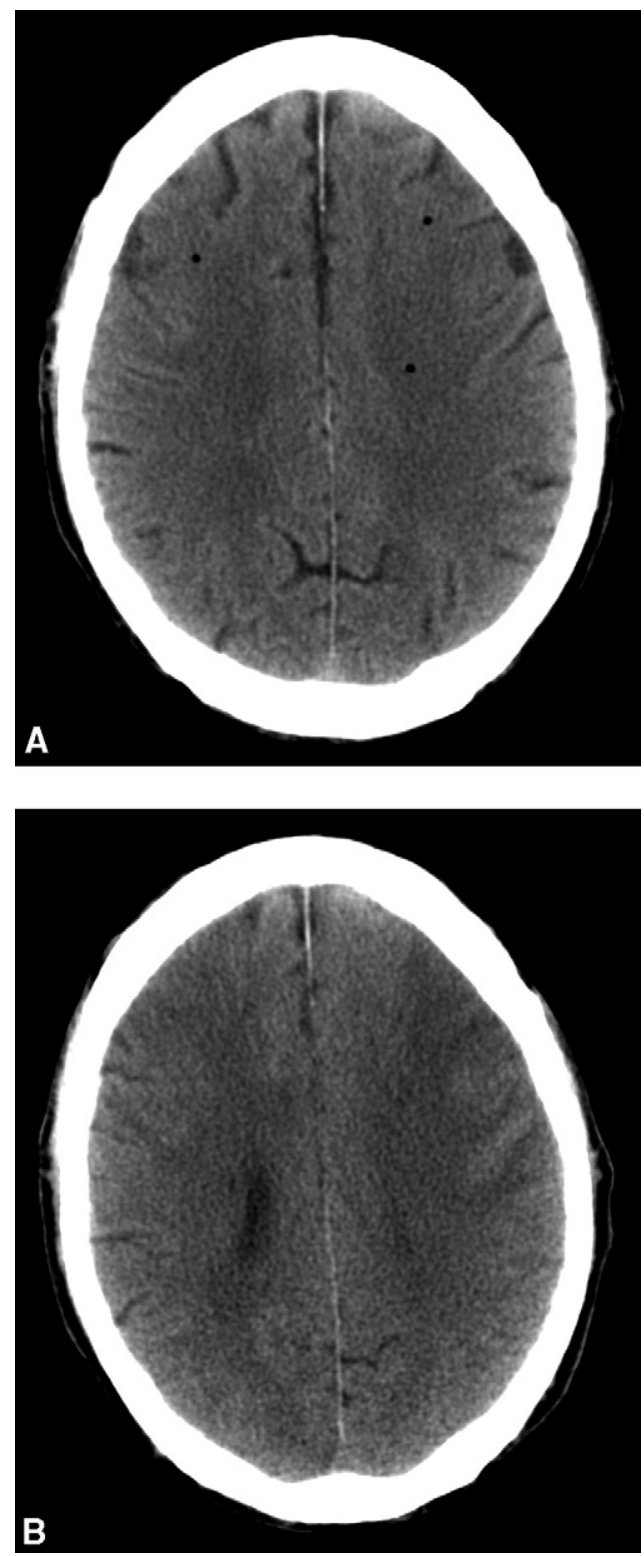

Figure 1. Computed tomographic scan of brain (A) immediately after seizures showing multiple focal hypodensities compatible with air in the subarachnoid space and (B) 7 days postoperatively showing extensive ischemic changes and edema in both cerebral hemispheres. 


\section{Discussion}

Although SAE rarely occurs, it is a recognized complication of thoracic trauma, including iatrogenic injuries. Intraoperative SAE after stapled wedge excision of a pulmonary nodule has been reported; transesophageal echocardiography identified air in the left atrium, but the patient had no neurologic sequelae. ${ }^{2}$

CAE has been reported after CT-guided needle localization ${ }^{3}$ and bronchoscopy with insufflation of oxygen at high pressure, ${ }^{4}$ but it has not been reported after a pulmonary resection. Neurologic sequelae are noted immediately after CAE. ${ }^{3-5}$ Our patient had no neurologic symptoms until 6 hours after extubation and 4 hours after commencement of NIPPV. We believe that air entered the circulation because of the increased airway pressure generated by BIPAP rather than intraoperatively. CAE has been reported after 2 weeks of BIPAP in a patient with post-bone marrow transplant pneumonitis. ${ }^{5}$

SAE requires the presence of a portal of entry and a pressure gradient to drive the gas into the circulation. In a spontaneously breathing patient, the pressure in the airways is lower than in the pulmonary veins. With the institution of positive pressure ventilation, the gradient alters in favor of entrainment of air into the pulmonary venous system. Whether the air was entrained through a fistulous communication at the lung periphery because of the surgery or a new communication secondary to NIPPV in an emphysematous lung is unknown. Both peripheral ${ }^{2,3}$ and centrally ${ }^{4}$ located pulmonary interventions have been implicated in air embolism.

The diagnosis of cerebral air embolus is often clinical; head CT is frequently normal ${ }^{3,4}$ or only shows areas of embolic infarc- tion. ${ }^{1,5}$ Intracranial air is rarely visualized. Hyperbaric oxygen therapy has been used to treat patients with $\mathrm{CAE},{ }^{4}$ but it is seldom used $^{1,3}$ because of the difficulties in making the diagnosis with certainty, transporting a critically ill patient, and accessing facilities that provide hyperbaric oxygen. With purely supportive patient treatment, CAE usually causes transient neurologic sequelae with complete recovery within 2 weeks ${ }^{1,3}$; when patients have died, this was attributed to other causes. ${ }^{5}$

We report a case of CAE after pulmonary wedge excision, of which we are not aware of any other reports. It is unusual to obtain radiologic evidence of the diagnosis, and its precipitation by noninvasive ventilation has not been reported after pulmonary surgery.

\section{References}

1. Brownlow HA, Edibam C. Systemic air embolism after intercostal chest drain insertion and positive pressure ventilation in chest trauma. Anaesth Intensive Care. 2002;30:660-4.

2. Hemmerling TM, Schmidt J, Bosert C, et al. Systemic air embolism during wedge resection of the lung. Anesth Analg. 2001;93:1135-6.

3. Kamiyoshihara M, Sakata K, Ishikawa $S$, et al. Cerebral arterial air embolism following CT-guided lung needle marking. J Cardiovasc Surg. 2001;42:699-700.

4. Wherrett CG, Mehran RJ, Beaulieu MA. Cerebral arterial gas embolism following diagnostic bronchoscopy: delayed treatment with hyperbaric oxygen. Can J Anesth. 2002;49:96-9.

5. Hung S-C, Hsu H-C, Chang S-C. Cerebral air embolism complicating bilevel positive airway pressure therapy. Eur Respir J. 1998;12:235-7.

\title{
Concurrent primary cardiac tumors
}

\author{
Tulsi Menon, MBBS, Yuki Watanabe, MBBS, and David Andrews, MBBS, FRACS, Perth, Australia
}

\section{Clinical Summary}

An 80-year-old woman was referred to a cardiologist with recurrent palpitations, atrial fibrillation, and flutter. Investigation with an echocardiogram revealed a mass (believed to be a myxoma) on the fossa ovalis, extending into the left atrium and then out near the right superior pulmonary vein, where it became frond-like and friable. She was subsequently referred for surgical intervention to remove the myxoma. She was otherwise relatively well.

From the Department of Cardiothoracic Surgery, Royal Perth Hospital, Perth, Western Australia, Australia.

Received for publication Feb 2, 2007; accepted for publication Feb 12, 2007.

Address for reprints: Tulsi Menon, MBBS, 19 Morgan Rd, Redcliffe WA 6104, Australia (E-mail: kaltul@optusnet.com.au).

J Thorac Cardiovasc Surg 2007;134:263-4

0022-5223/\$32.00

Copyright $\odot 2007$ by The American Association for Thoracic Surgery

doi:10.1016/j.jtcvs.2007.02.038
Intraoperatively, after the patient was commenced on bypass and the aorta was crossclamped, an incision to the atrial septum was performed on the tricuspid valve side of the fossa ovalis. Affixed to the atrial fossa was a sessile mass, the atrial myxoma, extending into the left atrium. Distant from this mass, situated in the posterior wall of the left atrium (near the origin of the right superior pulmonary vein), was a frond-like mass, a papillary fibroelastoma, with frond lengths measuring around $1.5 \mathrm{~cm}$ and the base densely filled with tentacles. Both tumors were excised, and the defects were closed. The patient was taken off bypass. Closure was performed in the routine manner.

The patient was transferred to the intensive care unit postoperatively, discharged to the ward 3 days later, and discharged home 11 days postoperatively. Histopathology of the resected left atrial lesions confirmed atrial myxoma and papillary fibroelastoma. Follow-up echocardiograms several months and more than 1 year postoperatively demonstrated no evidence of remaining tumor.

\section{Discussion}

Primary cardiac tumors are very uncommon, with myxomas as the most common benign primary cardiac tumor. Myxomas commonly 